\title{
Flash flood detection through a multi-stage probabilistic warning system for heavy precipitation events
}

\author{
L. Alfieri ${ }^{1}$, D. Velasco $^{2}$, and J. Thielen ${ }^{1}$ \\ ${ }^{1}$ European Commission - Joint Research Centre, Ispra, Italy \\ ${ }^{2}$ Center of Applied Research in Hydrometeorology (CRAHI), Barcelona, Spain
}

Received: 26 July 2010 - Revised: 15 December 2010 - Accepted: 19 January 2011 - Published: 1 March 2011

\begin{abstract}
The deadly combination of short to no warning lead times and the vulnerability of urbanized areas makes flash flood events extremely dangerous for the modern society. This paper contributes to flash flood early warning by proposing a multi-stage warning system for heavy precipitation events based on threshold exceedances within a probabilistic framework. It makes use of meteorological products at different resolutions, namely, numerical weather predictions (NWP), radar-NWP blending, and radar nowcasting. The system is composed by two main modules. First, a European Precipitation Index based on a simulated Climatology (EPIC) and probabilistic weather forecasts is calculated to pinpoint catchments at risk of upcoming heavy precipitation. Then, a Probabilistic Flash Flood Guidance System (PFFGS) is activated at the regional scale and uses more accurate input data to reduce the estimation uncertainty.

The system is tested for a high flow event occurred in Catalonia (Spain) in November 2008 and results from the different meteorological input data are compared and discussed. The strength of coupling the two systems is shown in its ability to detect areas potentially at risk of severe meteorological conditions and then monitoring the evolution by providing more accurate information with higher spatial-temporal resolution as the event approaches.
\end{abstract}

\section{Introduction}

Flash flood early warning is among the most challenging topics in the scientific research in hydrometeorology. Despite the large uncertainty embedded in Numerical Weather Predictions (NWPs) at fine resolution, the use of these products

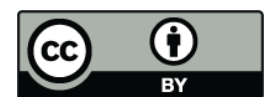

Correspondence to: L. Alfieri (lorenzo.alfieri@jrc.ec.europa.eu) is an inevitable choice to achieve a sufficient lead time for mitigating the effects of such hazardous events. Although the early detection of flash floods is highly uncertain, even very weak signals should be considered in the early warning stage. In fact, a pre-selection of areas where heavy precipitation is forecasted is important to correctly address further targeted analysis. This streamlines the triggering of prompt emergency actions, in case the early signal is confirmed.

In the recent literature, research has mainly faced the issue of flash flood early warning through hydrometeorological simulation of NWPs within distributed and semi-distributed hydrological models (e.g., Reed et al., 2007; Blöschl et al., 2008; Younis et al., 2008). Some empirical methods use instead a combination of rainfall thresholds and initial soil moisture conditions to predict severe events (Martina et al., 2006; Georgakakos, 2006; Collier et al., 2007; Javelle et al., 2010). However, most systems currently implemented for operational flash flood warning are adapted to specific regions and input data. This leads to a wide variety of systems which are difficult to transfer outside their calibrated regions without some prior knowledge on the selected area, particularly for ungauged catchments.

In this paper, we propose a multi-stage probabilistic warning system for heavy precipitation events with no calibration parameter, based only on rainfall threshold exceedances. Differently from existing meteorological products aimed at detecting extreme weather conditions (e.g., Lalaurette, 2003; Golding, 2009), the proposed method relates rainfall accumulations to the local drainage network. This makes it suitable to detect areas at risk of flooding, particularly for flash floods in small catchments driven by extreme rainfall intensities over short durations. The system is designed to (1) detect catchments at the continental scale (e.g. in Europe) where severe precipitation is forecasted and (2) subsequently downscale to local analyses as the event draws closer, by using different meteorological input data of increasing accuracy.

Published by Copernicus Publications on behalf of the European Geosciences Union. 
The full system is being tested in the Catalonian region, in the Eastern Spain, where different meteorological input data are operationally available.

The basic principle of this warning system is predicting extreme events by comparing the accumulated upstream precipitation with reference values corresponding to a low probability of occurrence (i.e., in the upper tail of its probability distribution). Although a number of simplifications are induced by not considering initial conditions and the hydrological processes, the strength of the method is the absence of calibration parameters and the easy transferability to any geographical context. The proposed system is fit to catchments with drainage area up to $1000-2000 \mathrm{~km}^{2}$ where the most hazardous events are induced by storms of duration up to $24 \mathrm{~h}$ (see e.g., Reed et al., 2007; Gaume et al., 2009) and often shorter than the basin time of concentration (Alfieri et al., 2008). As Guillot and Duband (1967) described in the Gradex method, the gradient of the statistical distribution of discharges tends to follow asymptotically that of rainfall, for high return periods. This behavior is more evident for small catchments, where the most severe events are caused by high rainfall depths over short durations, and the associated rainrates are well above the infiltration capacity of the soil.

\section{Meteorological data}

Probabilistic weather predictions are provided by COSMO (Consortium for Small-scale Modeling). Operational meteorological forecast considered is the Limited-Area Ensemble Prediction System (LEPS) of COSMO model (Marsigli et al., 2005). COSMO-LEPS consists of 16 members and are provided on a rotated spherical grid that covers a large portion of Europe with horizontal resolution of about $7 \mathrm{~km}$ ( $\sim 10 \mathrm{~km}$ before December 2009) and temporal resolution of $3 \mathrm{~h}$. COSMO-LEPS is initialized once a day at 12:00 UTC and spans $132 \mathrm{~h}$.

In addition, a long-term continuous meteorological climatology was created from a set of 30-year hindcasts (Fundel et al., 2010). It consists of a set of COSMO hindcasts, initialized every 3 days from ECMWF control run by using ERA 40 re-analysis dataset as initial and boundary conditions. A continuous climatology is obtained by joining the data of each subsequent forecast, to produce a seamless meteorological dataset that is coherent with operational COSMO-LEPS forecasts. Long-term coherent reference climatology is particularly useful for flash-floods, as they often take place in small watersheds, where little or no measurement is available.

High-resolution rainfall estimates based on radar measurements are used within the regional/local level approach of the warning system. The Catalan Weather Service (SMC) operates a regional network of four C-band weather radars that cover the whole Catalan domain $\left(32000 \mathrm{~km}^{2}\right.$ area). The spatial resolution of radar-based rainfall field is $1 \mathrm{~km}^{2}$ and the temporal resolution $6 \mathrm{~min}$. A radar processing system is included in the Catalan EHIMI early warning system (Corral et al., 2009) and provides real-time rainfall estimates. Moreover, a radar-based rainfall nowcasting with $2 \mathrm{~h}$ lead time (Berenguer, 2005) is currently operational in the EHIMI system and is particularly suitable for monitoring severe rainstorms.

Information on regional rainfall climatology has been made available by the Ministerio de Fomento (1999) with Intensity-Duration-Frequency (IDF) maps for Spain.

\section{The multi-stage warning cascade}

\subsection{A European precipitation index based on climatology}

The first stage of the forecasting chain is the continuous monitoring of the European domain for upcoming heavy precipitation through a European Precipitation Index based on Climatology (EPIC), which is calculated on a daily basis from the latest COSMO-LEPS weather forecasts. The Upstream cumulated Precipitation (UP ${ }_{d i}$ ) for each grid point of the domain is defined as the double summation of precipitation depth over the upstream area and over a certain duration $d i$ preceding the considered time $t$. Then, the EPIC index can be defined as

$$
\operatorname{EPIC}(t)=\max _{\forall d i}\left(\frac{U P_{d i}(t)}{\frac{1}{N} \sum_{y i=1}^{N} \max \left(U P_{d i}\right)_{y i}}\right) ; d i=\{6,12,24 \mathrm{~h}\}
$$

The annual maxima in the denominator of Eq. (1) are calculated from the COSMO climatology for each year yi ranging between 1 and $N=30$. The rationale of EPIC is to rescale the forecasted upstream precipitation by the corresponding mean of the annual maxima for the same duration, and then take the maximum value among the typical durations of storms producing flash floods. The resulting coefficient gives a measure of the severity of upcoming precipitation, and it can be easily expressed in terms of return period of the occurrence.

The strength of this methodology is the low computational requirement compared to the hydrological simulation, which is currently not feasible for the whole continental domain on the considered resolution $(1 \mathrm{~km})$. Some analyses previously carried out (not shown in this paper) indicate a strong correlation between EPIC and the simulated discharge, particularly for high flows. In particular, EPIC was found to produce very little underestimations of the severity of flood events, which is a desirable characteristic for an early warning system.

The precipitation index is operationally calculated for each $1 \mathrm{~km}$ grid cell of COSMO-LEPS domain and shown 
through the web interface of the European Flood Alert System (EFAS, http://efas-is.jrc.ec.europa.eu). As EPIC is calculated from an ensemble forecast, we show the probability of exceedance of two thresholds, i.e., $\mathrm{EPIC}_{\mathrm{MED}}=1$ (medium threshold) and $\mathrm{EPIC}_{\mathrm{HIGH}}=1.5$ (high threshold). Further, two sets of reporting points are created at the most downstream river pixel with at least 3 members out of $16(18.75 \%)$ above each threshold. They are plotted on a geo-referenced map to give a straightforward indication on where severe rainfall is forecasted for the subsequent five days. In addition, these points are taken as outlets where catchment-scale hydrological simulations are activated on a fine resolution from EFASFF (Alfieri et al., 2011).

It is worth noting that the calculation of EPIC is carried out on 1 by $1 \mathrm{~km}^{2}$ grid resolution, while COSMO ensemble weather forecasts have a resolution of $49 \mathrm{~km}^{2}$ $\left(100 \mathrm{~km}^{2}\right.$ before December 2009). Recent work by Sangati and Borga (2009) showed that the error in normalized rainfall and normalized peak discharge becomes significant when the rainfall resolution is coarser than the characteristic basin length. This becomes even more important for severe storms producing flash floods, which are often characterized by very high rainfall rates on small areas and strong spatial decorrelation. As a consequence, we set a minimum upstream area of $50 \mathrm{~km}^{2}$ for a catchment to be considered within the proposed methodology. In the web interface, every grid point exceeding a rainfall threshold is shown, while reporting points are created only for catchments bigger than $50 \mathrm{~km}^{2}$.

\subsection{The regional Probabilistic Flash Flood Guidance System (PFFGS) in Catalonia}

The second stage of the forecasting chain is the Probabilistic Flash Flood Guidance System (PFFGS) based on highresolution estimated rainfall fields provided operationally by regional radar networks. The PFFGS has been initially developed, set-up and tested in the Catalonia region, where the operational EHIMI system supports the present research. Similar in methodology to EPIC, the PFFGS provides probabilistic warnings for heavy precipitation events based on higher resolution input from observed and nowcasted rainfall fields, available only at the regional scale. According to the PFFGS methodology, the accumulated rainfall is spatially averaged on the upstream area by considering $1 \mathrm{~km}$ space resolution and 30-min time steps. For each grid cell, the upstream rainfall depth is computed for a duration corresponding to the concentration time of the catchment, according to the classical Rational Method (Chow et al., 1988). Since flash flood prone catchments have small upstream area, the considered rainfall durations are in the range $\mathrm{d}_{i}=\{0.5-24\} \mathrm{h}$. Concentration time $\left(t_{C}\right)$ is previously calculated at every grid cell by using Temez's equation (Ferrer, 1993).

The above described methodology was first applied to the reference precipitation climatology (IDF maps) to obtain accumulated rainfall indicators at every grid cell, by consid- ering the corresponding rainfall durations $d=t_{C}$. Each reference rainfall indicator is associated to a probability of occurrence (hazard) and a return period $T$. Operationally, the estimated and nowcasted rainfall indicators are compared to the corresponding reference value at each grid cell and the exceeded return period is considered to issue flood warnings. A map showing the exceeded return periods $T_{i}=\{2,5$, $10,25,50,100,200,500$ years $\}$ is generated every $30 \mathrm{~min}$. Reservoirs and regulated watersheds are taken into account by splitting the rainfall spatial averaging of upstream and downstream area. Similarly to EPIC, antecedent soil moisture conditions are not accounted in this method. Therefore, links to flood warnings should be made by integrating the information of PFFGS with additional parameters particularly for describing the initial conditions in the considered areas. Since the system is adapted to ensemble forecasts, probability maps of warning threshold exceedance are produced. PFFGS has been setup in three configurations to cope with precipitation products at different resolutions and, in particular, with different forecast lead times. Specifically, the PFFGS-2 uses radar precipitation nowcasts up to $2 \mathrm{~h}$ lead time, the PFFGS-6 uses the radar-NWP blending up to $6 \mathrm{~h}$ lead time, and the PFFGS-24 uses COSMO-LEPS ensemble forecasts up to $24 \mathrm{~h}$ ahead, thus producing a seamless forecasting chain with EPIC. The PFFGS-2 module takes advantage of Lagrangian persistence techniques applied to radar rainfall (Berenguer et al., 2005) and generates four 30 -min nowcasted rain-fields at the time $t=\{+30,+60,+90$, $+120 \mathrm{~min}\}$. The blended forecast product used in PFFGS-6 consists of short-term NWP that assimilates radar information through merging techniques (Atencia et al., 2010) and achieve improved forecast skills up to $6 \mathrm{~h}$ lead time, compared to the two initial products considered separately. Finally, in PFFGS-24, available COSMO-LEPS rainfall forecasts are processed and adapted to the resolution required for the system through a uniform resampling to $1 \mathrm{~km}$ grid resolution and $30 \mathrm{~min}$ time steps.

\section{Results and discussion}

An application of the above described approach is tested for an event of high flows that occurred on 2 November 2008 in the Llobregat catchment $\left(5000 \mathrm{~km}^{2}\right)$ and some smaller neighboring catchments of the Tarragona Region (Catalonia, Eastern Spain). It was chosen as case study because different sources of meteorological input data were available (i.e., COSMO-LEPS forecast, radar-NWP blending, radar nowcast) and discharge measurements were collected at automatic stream gauges of the Llobregat river. Up to $130 \mathrm{~mm}$ cumulated rainfall was collected on 2 November in the Tarragona region and a peak discharge of $400 \mathrm{~m}^{3} \mathrm{~s}^{-1}$ was measured in the lower reach of Llobregat river (10 year return period approximately), though no flooding occurred. Weather systems that generate severe events in Catalonia often develop 


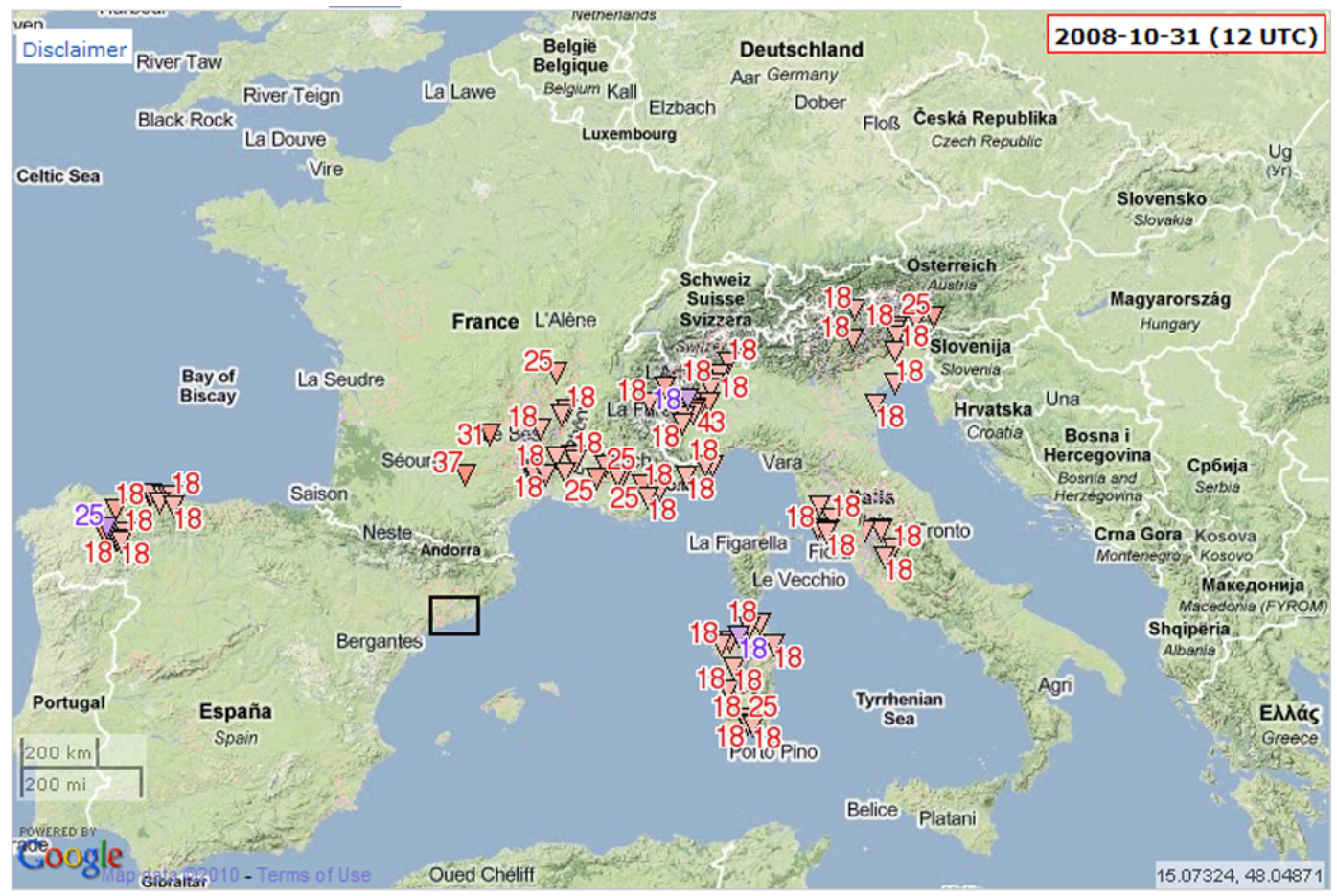

Fig. 1. EPIC in the web interface for COSMO-LEPS forecast of 31 October 2008 12:00 UTC. Reporting points are plotted through triangles. Probability of exceeding warning thresholds are shown with red (EPIC $\left.\mathrm{MED}_{\mathrm{N}}\right)$ and purple $\left(\mathrm{EPIC}_{\mathrm{HIGH}}\right)$ shadings, with the corresponding values aside each point (\%). A rectangle is drawn to indicate the spatial extent of the map in Fig. 2.

within very short spans and produce highly variable rainfall rate fields. Although the event was not among the most severe ones it is useful to describe the sequence of steps involved in the warning process, and how different weather products can first pinpoint and predict more accurately the characteristics of the events as they approach.

A first indication from EPIC index at the European scale is shown in Fig. 1 for COSMO-LEPS forecast of 31 October 2008, 12:00 UTC. Overall, 85 reporting points above

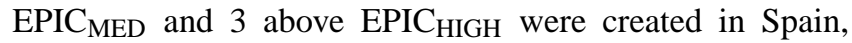
France and Italy, with probability up to $65 \%$ of exceeding the medium threshold (in North-Western Italy) and up to 25\% of exceeding the high threshold (in North-Western Spain). Follow-up reports confirmed some events of heavy precipitation and flooding over the following days in the Italian regions of Piedmont (north-west), Friuli (north-east, Tagliamento river basin) and Sardinia, as well as in the SouthEastern France (Provence, Alpes, Rhone Region) (see Alfieri et al., 2011). In Catalonia, no reporting points were created, though in some flash flood prone catchments southern of Barcelona and in the Tarragona region (typically ungauged Mediterranean torrents) we found some probability of exceeding both the medium (12\%) and high $(6 \%)$ threshold (see Fig. 2). Follow-up reports from the local press and media confirmed the event as high alert flow, though below the highest level (i.e., severe alert). Some coastal cities (Ven- drell, Salou) were damaged by local flooding and some connections of the regional railway were disrupted. In Fig. 3 we show the ensemble EPIC index for the Vendrell outlet (ungauged catchment) pinpointed in Fig. 2. Figure 3 shows a clear signal of heavy precipitation about two days ahead, when the event was recorded. Although the EPIC ensemble mean was slightly above 0.5 , the $87.5 \%$ forecast quantile was above the medium threshold.

The probability of exceedance of EPIC warning thresholds is often found rather low (i.e., $P$ (EPIC $>$ EPIC $\left._{\text {MED,HIGH }}\right)<$ $50 \%$ ) also when flash flood events do occur. A probable explanation to this outcome is that different LEPS members simulate the same event in slightly shifted areas. Further, small scattered storms cannot be captured by the resolution of meteorological forecasts, especially for long lead times. As a result, a higher success in predicting a severe event is achieved when the signal detected by the EPIC index is spread through a large area, rather than very localized, even though the probability of threshold exceedance is relatively low. Such findings can be interpreted as "spatial persistence", which is linked and complementary to the "temporal persistence" of subsequent forecasts (Bartholmes et al., 2009) as a way to improve the warning skill. In fact, this helps delineating the limits of predictability of current NWP with regard to short and severe precipitation events. Further, it stresses the importance of using limited area ensemble 


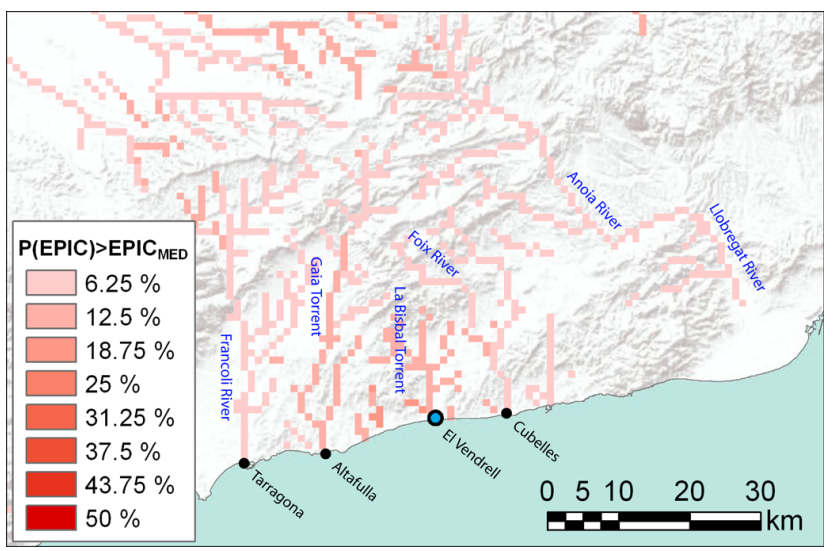

Fig. 2. EPIC probabilities for COSMO-LEPS forecast of 31 October 2008 12:00 UTC. Probabilities of medium threshold exceedance are shown in red shadings. Vendrell outlet is also shown with a blue circle.

forecasts with high spatial resolution, for better characterizing the forecast reliability and the areas potentially at risk of flash flooding.

After the EPIC index spots areas at risk of extreme precipitation, the PFFGS-24 is activated at the regional scale. It consists of a similar analysis to that of EPIC, the major difference being the reference thresholds. Indeed, while EPIC thresholds are derived from a simulated climatology (i.e., COSMO 30-year), the PFFGS warning thresholds are derived from interpolation of actual rainfall point measurements at the ground. Results of PFFGS-24 (not shown) are similar to those provided by EPIC. In particular, the spatial pattern of warnings is partially shifted eastwards compared to PFFGS-2, and peak rainfall intensities of convective storms are smoothed and spread over larger areas. PFFGS-6 enhances the detection of small scale storms and associated floods due to including radar data in the blended meteorological forecasts. Finally, short lead time forecasts in PFFGS-2 (up to $2 \mathrm{~h}$ ) provide a more accurate spatial description of the warnings, especially in small fast-reactive watersheds (i.e., area smaller than $100 \mathrm{~km}^{2}$ ), where the flow routing plays a minor role and floods are mainly driven by short-lived intense storms.

Results of the high resolution PFFGS-2 (radar nowcast) are shown in Fig. 4. The main flood warnings are correctly located in catchments around Tarragona (Francoli river, Salou and Vendrell torrents, $200-800 \mathrm{~km}^{2}$ upstream area). Very locally some warnings with $T=25$ years were estimated, though in general, warnings were below $T=10$ year return period. Furthermore, probabilistic flood warning maps of the PFFGS-6 (blending radar-NWP) for 6 hour forecast lead time are shown in Fig. 5 for return periods of 2 and 5 years. Maps indicate low probability of exceeding both the 2 and 5 year return period thresholds $(<35 \%)$. Results in Fig. 5 are in agreement with the EPIC index. However, warning loca-

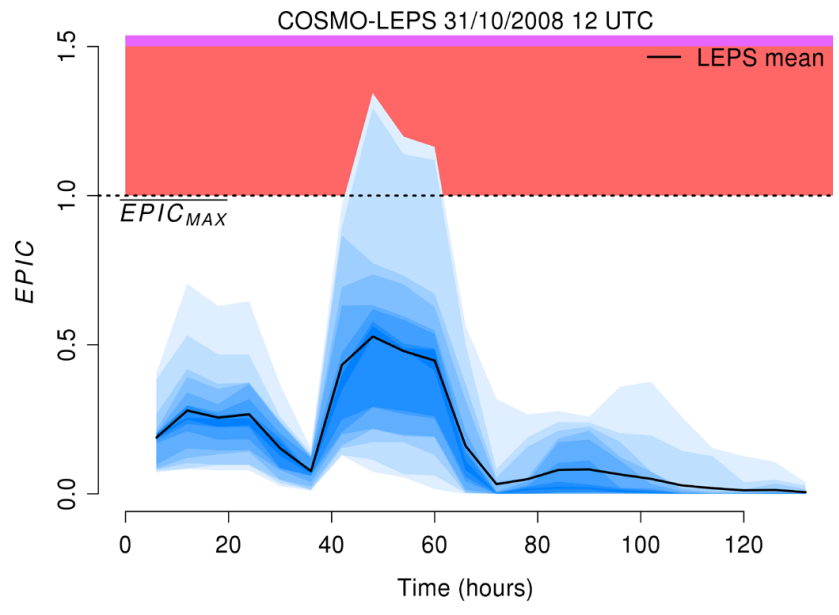

Fig. 3. Ensemble EPIC index at the Vendrell outlet indicated in Fig. 2, for COSMO-LEPS forecast of 31 October 2008 12:00 UTC.

tions and extensions shown in PFFGS-6 are slightly different from those in PFFGS-2, which provides higher accuracy at the expense of lower warning lead time. The main affected area identified by PFFGS-2 is slightly reduced, compared to PFFGS-6, and shifted towards the Tarragona region. Further, the radar nowcasting provides a more detailed description of the rainfall field, giving an accurate qualitative picture of the size and the shape of convective fronts and their evolution.

\section{Conclusions}

A probabilistic warning system for heavy precipitation events is presented hereby and results are discussed for an event occurred in November 2008. The main goals of the proposed warning system are: (1) to set up an integrated multi-level approach aimed at detecting severe storms potentially leading to flash floods, working on different spatial and temporal scales; (2) to provide the end-users with probabilistic warning maps easy to read; (3) to create a system with low computational cost, able to monitor very large domains (e.g., the whole Europe) and to downscale to fine resolution analysis when some signal of upcoming flooding is detected; (4) to achieve increased system robustness against operational failures by integrating independent warning modules, which partially overlaps in scale ranges.

We defined a new simple dimensionless index (EPIC) to measure the severity of forecasted rainfall. It is a combination of a pure meteorological product and the catchment river network, useful to detect small catchments at risk of upcoming flash floods driven by short-lived rain storms. The proposed EPIC index is a first indication to identify areas where severe rainfall is forecasted. As severe events draw closer, the Probabilistic Flash Flood Guidance System (PFFGS) is activated and uses more accurate rainfall data, which gives enhanced skills on small-scale flash-flood prone catchments. 

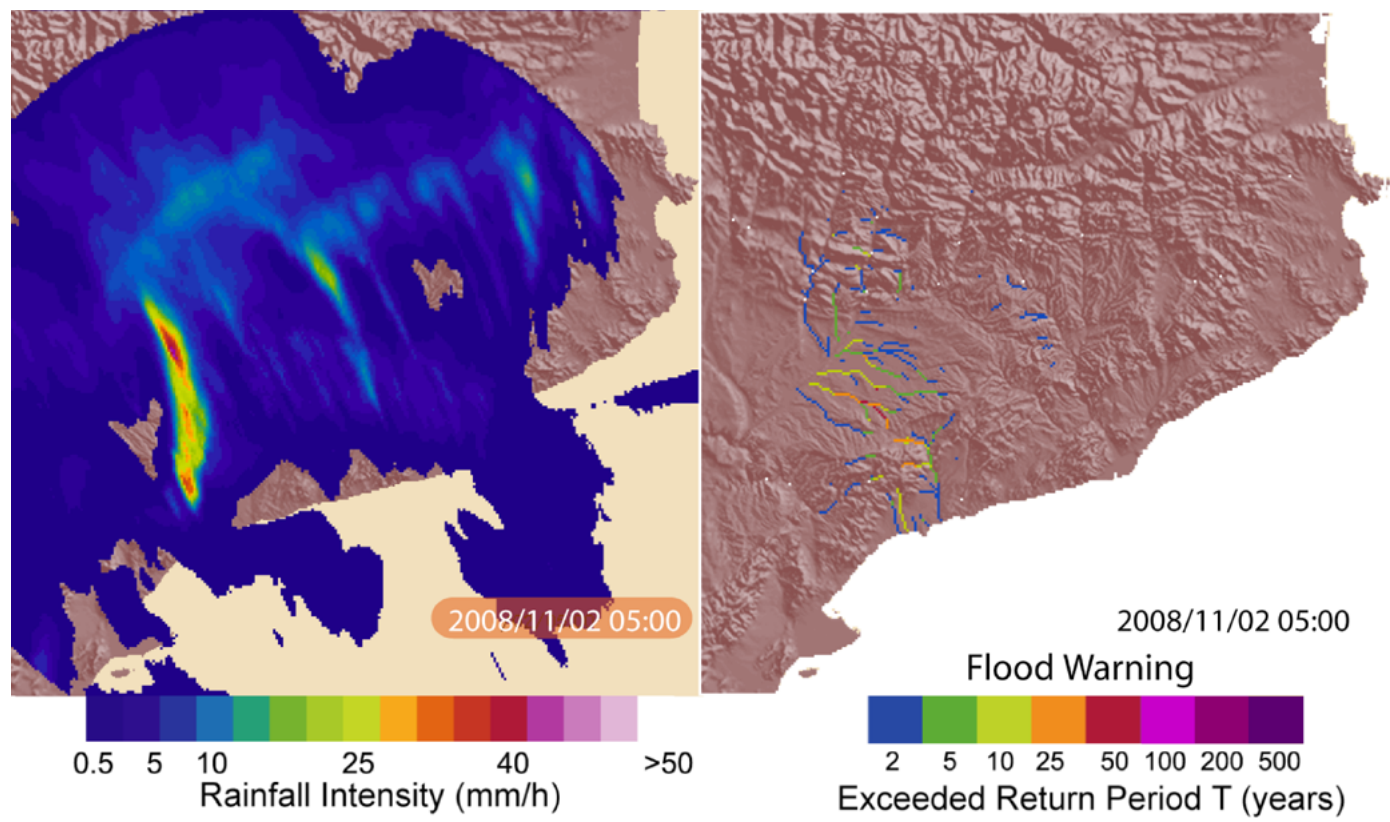

Fig. 4. PFFGS-2 for the Catalonian region for 2 November 2008. 30-min radar rainfall nowcast map (left panel) and flood warning map (right panel) in terms of exceeded return period.
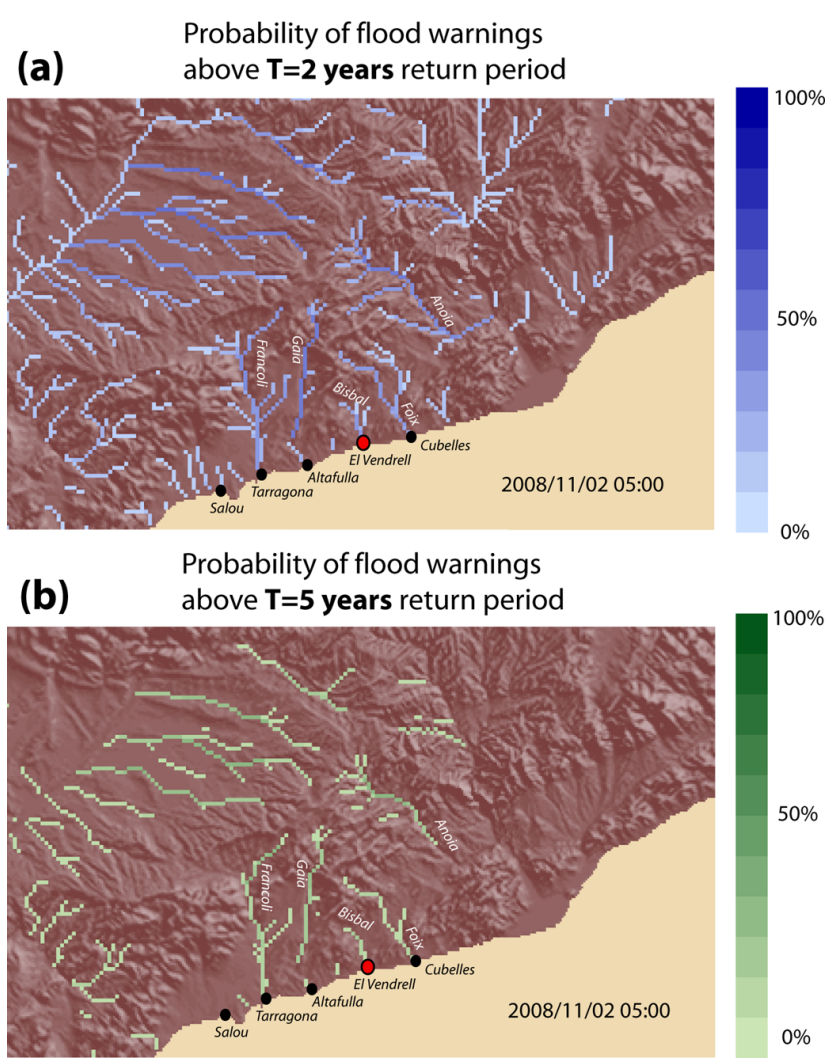

Fig. 5. PFFGS-6 probabilistic flood warning maps for 2 November 2008, with $6 \mathrm{~h}$ lead time. Probability of exceeding the 2 year (top panel) and 5 year (bottom panel) return period.
Because of its own nature, this warning system can be linked only to a specific kind of flood occurrences and provides results sometimes very different to those based on hydrological simulations. In fact, the hydrological components related to the rainfall-runoff process (i.e., initial water stage, soil moisture, accumulated snow and melting process, among others) are not considered. On the other hand, the proposed method has the strength of producing no additional uncertainty, as there are no calibration parameters. This is of crucial importance for an operational implementation to large areas like Europe, where the aim is to detect events in small catchments often without gauge measurements for calibration and validation. Besides, the computational requirements of this method are much reduced in comparison to actual hydrological simulations. This enables the implementation of the system on the European domain using a fine grid resolution $(1 \mathrm{~km})$.

Further steps are foreseen in PFFGS-2 and PFFGS-6 with the use of radar ensemble precipitation nowcasting (Pegram at al., 2010). The uncertainty associated to radar rainfall estimation will be used to improve the statistical characterization of the warnings, particularly at small scales.

Acknowledgements. The authors acknowledge the IMPRINTS project (FP7-ENV-2008-1-226555) for financial support.

Edited by: M.-H. Ramos

Reviewed by: two anonymous referees 


\section{References}

Alfieri, L., Laio, F., and Claps, P.: A simulation experiment for optimal design hyetograph selection, Hydrol. Process., 22, 813$820,2008$.

Alfieri, L., Smith, P. J., Thielen-del Pozo, J., and Beven, K. J.: A staggered approach to flash flood forecasting case study in the Cévennes region, Adv. Geosci., 29, 13-20, doi:10.5194/adgeo29-13-2011, 2011.

Atencia, A., Rigo, T., Sairouni, A., Mor, J., Bech, J., Vilaclara, E., Cunillera, J., Llasat, M. C., and Garrote, L.: Improving QPF by blending techniques at the Meteorological Service of Catalonia, Nat. Hazards Earth Syst. Sci., 10, 1443-1455, doi:10.5194/nhess-10-1443-2010, 2010.

Bartholmes, J. C., Thielen, J., Ramos, M. H., and Gentilini, S.: The european flood alert system EFAS - Part 2: Statistical skill assessment of probabilistic and deterministic operational forecasts, Hydrol. Earth Syst. Sci., 13, 141-153, doi:10.5194/hess-13-1412009, 2009.

Berenguer, M., Corral, C., Sánchez-Diezma, R., Sempere- Torres, D.: Hydrological validation of a radar-based nowcasting technique, J. Hydrometeorol., 6, 532-549, 2005.

Blöschl, G., Reszler, C., and Komma, J.: A spatially distributed flash flood forecasting model, Environ. Modell. Softw., 23, 464478, 2008

Chow, V. T., Maidment, D., and Mays, L.: Applied Hydrology, Ed. McGraw-Hill, 1988.

Collier, C. G.: Flash flood forecasting: What are the limits of predictability?, Q. J. Roy. Meteor. Soc., 133, 3-23, 2007.

Corral, C., Velasco, D., Forcadell, D., Sempere-Torres, D., and Velasco, E.: Advances in radar-based flood warning systems. The EHIMI system and the experience in the Besos flash-flood pilot basin. Flood Risk Management: Research and Practice, edited by: Allsop W., Samuels P., Harrop J., and Huntington S., Taylor \& Francis Group, London, ISBN 978-0-415-48507-4, 2009.

Ferrer, F. J.: Recomendaciones para el cálculo hidrometeorológico de avenidas, CEDEX, Madrid, 1993.

Fundel, F., Walser, A., Liniger, M. A., and Appenzeller, C.: Calibrated precipitation forecasts for a limited-area ensemble forecast system using reforecasts, Mon. Weather Rev., 138, 176-189, 2010.

Gaume, E., Bain, V., Bernardara, P., Newinger, O., Barbuc, M., Bateman, A., Blaškovièová, L., Blöschl, G., Borga, M., Dumitrescu, A., Daliakopoulos, I., Garcia, J., Irimescu, A., Kohnova, S., Koutroulis, A., Marchi, L., Matreata, S., Medina, V., Preciso, E., Sempere-Torres, D., Stancalie, G., Szolgay, J., Tsanis, I., Velasco, D., and Viglione, A.: A compilation of data on European flash floods, J. Hydrol., 367, 70-78, 2009.
Georgakakos, K. P.: Analytical results for operational flash flood guidance, J. Hydrol., 317, 81-103, 2006.

Golding, B. W.: Long lead time flood warnings: Reality or fantasy? Meteorol. Appl., 16, 3-12, 2009.

Guillot, P. and Duband, D.: La méthode du gradex pour le calcul de la probabilité des crues à partir des pluies, AISH Publ. no. 84, 560-569, 1967.

Javelle, P., Fouchier, C., Arnaud, P., and Lavabre, J.: Flash flood warning at ungauged locations using radar rainfall and antecedent soil moisture estimations, J. Hydrol., 394, 267-274, 2010.

Lalaurette, F.: Early detection of abnormal weather conditions using probabilistic extreme forecast index, Q. J. Roy. Meteor. Soc. 129, 3037-3057, 2003.

Marsigli, C., Boccanera, F., Montani, A., and Paccagnella, T.: The COSMO-LEPS mesoscale ensemble system: Validation of the methodology and verification, Nonlinear Proc. Geoph., 12, 527 536, 2005.

Martina, M. L. V., Todini, E., and Libralon, A.: A Bayesian decision approach to rainfall thresholds based flood warning, Hydrol Earth Syst. Sci., 10, 413-426, doi:10.5194/hess-10-413-2006, 2006.

Ministerio de Fomento: Máximas lluvias diarias en la España Peninsular, Dirección General de Carreteras, Madrid, 1999.

Pegram, G., Llort, X., and Sempere-Torres, D.: Radar-rainfall Separating signal and noise fields to generate meaningful ensembles, Atmos. Res., doi:10.1016/j.atmosres.2010.11.018, in press, 2010.

Reed, S., Schaake, S., and Zhang, Z.: A distributed hydrologic model and threshold frequency-based method for flash flood forecasting at ungauged locations, J. Hydrol. 337, 402-420, 2007.

Sangati, M. and Borga, M.: Influence of rainfall spatial resolution on flash flood modelling, Nat. Hazards Earth Syst. Sci., 9, 575584, doi:10.5194/nhess-9-575-2009, 2009.

Younis, J., Anquetin, S., and Thielen, J.: The benefit of highresolution operational weather forecasts for flash flood warning, Hydrol. Earth Syst. Sci., 12, 1039-1051, doi:10.5194/hess-121039-2008, 2008. 